\title{
CLAVES POLÍTICAS \\ EN LAS COMEDIAS DE CALDERÓN: \\ EL CASO DE EL MAYOR ENCANTO AMOR
}

Frederick de Armas

Department of Romance Languages and Literatures

University of Chicago

1115 E. 58th St.

Chicago, IL 60637. USA

fdearmas@uchicago.edu

[Anuario calderoniano (ISSN: 1888-8046), 4, 2011, pp. 117-144]

En años recientes y sobre todo en Europa ha habido un cierto desasosiego ante las recientes interpretaciones políticas e ideológicas de la comedia, incluyendo las fiestas palaciegas de Calderón de la Barca. Ignacio Arellano, por ejemplo aconseja contra los excesos a que puede llegar la crítica con este tipo de interpretación «la obsesión por los elementos ideológicos de la comedia deriva a menudo en aplicación irrelevante de estas cuestiones a comedias en las que nada de ello se trata» ${ }^{1}$. No es que rechace este tipo de interpretación sino que ad-

\footnotetext{
${ }^{1}$ Arellano, 2005, p. 117.
} 
vierte que no puede partir de la nada. Creo que lo que les preocupa a algunos críticos son algunos de los excesos del historicismo contemporáneo. Es justamente este deseo de ir más allá de lo que puede hallarse en el texto lo que ha llevado a un desasosiego. En su magistral edición de las comedias de Calderón en la Biblioteca Castro, Santiago Fernández Mosquera hace un inusitado paréntesis en el segundo volumen para mostrar su inquietud ante las repetidas interpretaciones políticas de una fiesta palaciega, El mayor encanto, amor: «En las últimas décadas se han interpretado estas fiestas mitológicas en clave circunstancial y política. Se ha querido ver que, tras la aparente lisonja de una representación cortesana, se escondía un subtexto de fuerte crítica personal hacia el rey y hacia el valido por su mal gobierno. En el caso de El mayor encanto, amor, se ha identificado a Felipe IV con Ulises y a Circe con Olivares, quien tendría secuestrado física y mentalmente al Rey-Ulises en su Palacio del Buen Retiro... las advertencias y los insultos que sufriría el propio monarca y el ministro en la representación serían tan fuertes que, más allá de perder toda proporción y rotura del decoro, habría llevado a la desgracia a quien los hubiese propuesto y planeado» ${ }^{2}$.

Para este crítico, entonces, tal clave no puede estar presente ya que Calderón carecería de toda prudencia al diseñar la obra como insulto al soberano y a su privado. En uno de sus artículos, añade Fernández Mosquera: «Sin embargo, desde que Frederick de Armas en el año 1986 propuso abiertamente tales interpretaciones, el caudal de estudios ha crecido muy espectacularmente y ha llegado a extremos interpretativos que sí dibujan en Calderón una suerte de peligroso opositor oculto que expone crípticamente opiniones discrepantes que para la época eran abiertamente revolucionarias. E incluso, desde los primeros momentos de esta tendencia hermenéutica, si las alegorías señaladas y ya discutidas hubiesen sido ciertas y entendidas como tales, el impacto cortesano habría sido enorme y grave, seguramente "revolucionario"»3. No sé qué propicia estrella o qué funesto horóscopo me llevó a ser la causa de esta tempestad hermenéutica. Y no es que tal turbulencia no se encuentre en otros sitios - mucho se ha escrito sobre las claves de Shakespeare, sobre el por qué de su uso de la tem-

2 Fernández Mosquera, 2007, p. xxv.

${ }^{3}$ Fernández Mosquera, 2008, p. 224. 
pestad virgiliana y de su Próspero como figura positiva y negativade un rey cuya magia puede asociarse con $\mathrm{Medea}^{4}$. Ya que el tipo de interpretación que crea este desasosiego en algunos críticos está tan difundida, quisiera retornar El mayor encanto, amor en busca de soluciones. Lo que quisiera hacer en este ensayo es lo siguiente: (1) repasar lo que se ha escrito sobre los elementos políticos de la obra en los últimos treinta años para analizar las diferentes etapas por las que hemos pasado y así tratar de elucidar los fundamentos de las claves políticas; (2) repasar el contexto que me llevó a tal interpretación para comprender sus causas, y (3) ampliar la interpretación de El mayor encanto, amor teniendo en cuenta los problemas que han surgido.

\section{LA CRÍTICA}

Para este breve análisis de la crítica, podríamos comenzar con Sebastian Neumeister, el primero en resaltar la importancia política de las fiestas cortesanas en 1978. Aunque no recurre a nuestra obra, su detallado e innovador libro explica (uso la traducción española del 2000): «Durante demasiado tiempo la mirada sólo se ponía en el texto de estos dramas sin el contexto cultural e histórico y sin tomar en consideración su función en la corte» ${ }^{5}$. Estudia la importancia de la mitología en estas obras: «Si en el palacio real del Buen Retiro, en el centro de la potencia mundial española, los dioses de la antigüedad precristiana experimentan un regreso triunfal, es gracias a... el lugar que ocupan en un sistema cuyos elementos están orientados como en una elipse alrededor de sus dos centros, monarquía e iglesia» ${ }^{6}$. La fiesta puede tener sentido panegírico. Por otra parte: «La discrepancia creciente entre la pretensión de los reyes españoles y la verdadera situación del estado, ya se mostraba políticamente bajo Felipe IV... una

4 «Thus, even if Prospero speaks here to all good intents, the image that accompanies and haunts the one he now projects is the image of a magic, a power that can destroy - the type of magic with which Medea was primarily associated. The capacity that a transcendent power has for destruction was also an issue, probably the central issue, for the Parliament of 1610. If the king were allowed to levy impositions... then his power could grow to the point of their destruction» (Hamilton 1990, p. 127).

${ }^{5}$ Neumeister, 2000, p. 1.

${ }^{6}$ Neumeister, 2000, p. 9. 
imagen de la nación ahora la imagen de su malogro» ${ }^{7}$. Teniendo a Neumeister como precursor, pasemos ahora a las tres etapas en que podemos dividir la crítica de El mayor encanto, amor. La primera, desde 1980 hasta 1992 incluye los inicios y llega hasta la culminación teórica del acercamiento político. Desde 1992 al 2000 pasamos por un segundo período en el que se desarrollan y transforman las interpretaciones a veces de manera muy original. Y tercero, desde el 2000 hasta el presente tenemos una etapa en la que los excesos interpretativos han llevado a algunos estudiosos a delimitar las interpretaciones y aconsejar contra la exuberancia imaginativa. Otros recalcan los aciertos de esta práctica hermenéutica reiterando y llevando aun más lejos sus implicaciones.

Comencemos con el primer período. Cuando J. Brown y J. H. Elliott publicaron su libro sobre el palacio del Buen Retiro, explicaron claramente que para Olivares, el rey debería de ser el centro o sol de la corte, alrededor del cual los poetas y cortesanos giraban y brillaban. Los poetas debían contribuir con sus piezas laudatorias a la gloria del reinado ${ }^{8}$. Brown y Elliott aluden veladamente a una posible crítica cuando explican que el palacio se construyó en mal momento - en tiempo de guerra y problemas económicos ${ }^{9}$. Añaden que este no era el momento para que el rey se divirtiera presenciando El mayor encanto, amor, debido a la guerra con Francia: «a satirical piece making the rounds early in June speaking mordantly of the King of France being on campaign, and the King of Spain in retreat (en el Retiro) $»^{10}$.

De allí a mi interpretación política de la obra en The Return of Astraea hay sólo un paso: la isla de Circe es el Retiro y la maga es el

7 Neumeister, 2000, p. 296.

8 «Shinning in the reflected splendor of his patronage, the leading poets, playwrights and artists of the age would all revolve around him, magnifying his glory and giving luster to his reign" (1980, p. 40).

9 «A splendid court and palace were brought into being during a decade when Spain was racked by military reverses and economic crisis. In the midst of poverty and defeat, the Retiro and all it contained became a symbol of bad government and of the wasteful expenditure of financial resources» (1980, p. viii).

${ }^{10}$ Brown y Elliott, 1980, p. 196. La guerra con Francia duraría hasta 1659 cuando se firma la Paz de los Pirineos donde también se afirma el futuro casamiento de Luis XIV de Francia con la hija de Felipe IV, María Teresa. 
privado que atrapa al rey en festividades en momentos dificiles para el reino ${ }^{11}$. Cuando el libro se publicó en 1986, muchas de las reseñas resaltaron la crítica política en mi libro aunque yo sólo le dedicaba un capítulo a este acercamiento. Y como si este fuera el momento ideal para realzar este tipo de análisis, dos años después, Francisco Ruiz Ramón publicaba su libro Celebración y catarsis, donde afirma: «Nuestros grandes dramas clásicos responden, en realidad, a la doble función del teatro: de una parte, la función celebrativa, que le permite a una sociedad afirmar sus propias creencias y estimaciones, auto-confirmando su visión del mundo y su ideología, difusa o no; pero también, por otra parte, la función catártico-conjuradora, que permite conjurar los malos espíritus, las sombras y fantasmas agobiantes» ${ }^{12}$. También de 1988 es el libro de Thomas A. O'Connor sobre el teatro mitológico de Calderón. Aunque acepta la equivalencia entre el rey y Ulises y entre Circe y los encantos del Buen Retiro, prefiere estudiar el papel de la mujer. Para equilibrar en algo la misoginia Calderón sustituye a Júpiter y Mercurio con Juno e Iris, proveyendo agencia a la mujer ${ }^{13}$.

En 1989 William R. Blue incluye un capítulo sobre El mayor encanto, amor en su libro The Comedia: Art and History, donde habla de la polisemia del teatro que incluye referencias históricas.

Además de lo ya dicho por otros sobre Ulises y Circe, Blue añade que Antistes se relaciona con los arbitristas y Aquiles puede ser el fantasma de Felipe II. El gran acierto de Margaret Greer en su libro The Play of Power (1992) es el añadir a las interpretaciones políticas ya expuestas un aparato teórico claramente formulado. Para ella, los textos pueden estudiarse a través de tres niveles. Primero el texto del poder monárquico que se representa a través del espectáculo donde el rey mismo es el primer actor pues los cortesanos lo observan cuando ve representar una comedia ${ }^{14}$. Segundo, tenemos el texto político que

11 Se puede ver claramente que Calderón modificó el programa de Lotti, dejando fuera un gigante eremita que representaba el Retiro. Es cierto que Calderón incluye un gigante jocoso, como explica Fernández Mosquera (2008, p. 215). Para mí tal gigante no tiene nada que ver con el eremita moralizante. En la segunda edición de la obra de Brown y Elliott recalcan que el gigante se convierte en esclavo de Circe (2003, p. 207).

12 Ruiz Ramón, 1988, p. 21.

13 O'Connor, 1988, pp. 180-181.

14 Greer, 1992, p. 82. 
alaba a los monarcas como nuevos dioses, creando genealogías nuevas. Pero este segundo texto puede engendrar comparaciones nada acertadas: «can be a two edged sword» ${ }^{15}$. Por último, tenemos el texto particular que se muestra abierto a diferentes interpretaciones según los eventos del momento ${ }^{16}$. Es así que repite las correspondencias entre Felipe IV y Ulises y el palacio del Buen Retiro y los encantos de Circe.

Con Greer culmina el primer período interpretativo y de allí pasamos al segundo, el de las transformaciones. De 1993 y 1994 son las versiones españolas e inglesas de un ensayo de Susana Hernández Araico. Sigo la versión inglesa. Hernández Araico incluye dos elementos importantes. Primero, analiza detalladamente cambios hechos por Calderón a la escenografia de Cosme Lotti y en particular: «With the allegorical character of Virtue replaced by Achilles, the symbolic association of the former with Olivares is automatically transferred to Circe» ${ }^{17}$.Y segundo, aclara que Calderón dibuja a Circe como personaje complejo que no tiene nada de burlesco para así representar a Olivares con decoro ${ }^{18}$. De 1994 es la tesis doctoral de Kerry Wilks, quien también enfatiza que Circe es un personaje complejo y dice lo mismo de Ulises. Para ella, el comportamiento de Ulises no es nada ideal pues primero se deja llevar por el orgullo y luego por la pasión. Por lo cual, también hay crítica al rey ${ }^{19}$. De este mismo año es también el estudio de Aurora Egido que aúna la obra al auto sacramental, Los encantos de la culpa, enfatizando así las alegorías morales. Su estudio no menciona posibles interpretaciones políticas, sino que se concentra en lo espectacular. Son las mutaciones técnicas lo que le interesan $^{20}$. Y también de 1994 es el libro de Kristiaan P. Aercke, Gods

15 Greer, 1992, p. 87.

16 «In proposing that Calderón deliberately created a polysemic structure, I do not suggest that he intended to write an open text in the twentieth century sense of total relativism, but once constructed on a hermeneutic tradition of bounded pluralism» (Greer, 1992, p. 123).

17 Araico, 1994, p. 123.

18 Araico, 1994, p. 125.

19 "Within the play we do not find the image of the classical hero common within the comedia tradition, but rather a man debilitated by his weaknesses... the plays political message, then, begins to point directly at the king instead of placing the blame solely at the privados feet» (Wilks, 1994, p. 40).

${ }^{20}$ Egido, 1994, p. 34. 
at Play donde se estudian fiestas barrocas en Italia, España y Francia ${ }^{21}$. Comienza explicando que el Retiro es la Circe de Felipe y que Olivares participa en la creación de Circe, o sea que él también es Circe. Pero Aercke muestra la reversibilidad de la advertencia contra el nuevo palacio. Circe transforma a Ulises teniendo una función catalizadora en la que él se da cuenta de su deber y ella comprende que puede amar: «She transforms a world, a court, a person and herself... Circe, quite simply is the "spirit" of the Retiro. She is able to turn her island (the palace) into a civilizing place»" ${ }^{22}$. Vemos como poco a poco las transformaciones de Circe van metamorfoseándose en una serie de diversas interpretaciones políticas de esta obra de Calderón. Entre el segundo y el tercer período, encontramos como un paréntesis lúdico. Marcella Trambaioli, subraya elementos entremesiles y lúdicos en ésta y otras comedias palaciegas ${ }^{23}$.

Con el año 2000 pasamos a un tercer período donde el cuestionamiento de esta práctica, va acompañado de reiteraciones aun más vehementes de las interpretaciones políticas. En este año, Melveena McKendrick publica su libro sobre el teatro de Lope de Vega en el que por un lado defiende interpretaciones políticas y por el otro decide imponer reglas más precisas a éstas. El decoro, la prudencia y la cortesía son cualidades esenciales para poder criticar. Técnicas de distanciamiento permiten un «decir sin decir», frase tomada de Bances Candamo. Otros aplicarán sus reglas a Calderón ${ }^{24}$. Por otra parte, Margaret Greer y Frederick de Armas reiteran los argumentos políti-

21 Estudia el Sant'Alessio escrito para celebrar en 1632 el nuevo palacio de la familia de Maffeo Barberini, quien fue elegido Papa Urbano VIII en 1623. Es una ópera con el libretto de Giulio Rospligliosi y música de Stefano Landi (1994, p. 116). También se incluyen otras obras tales como el Ercole amante (1662) ópera a petición de Luis XIV y Il pomo d'oro (1668) para Leopoldo I de Austria.

22 Aercke, 1994, p. 158.

23 Trambaioli, 1998a y 1998 b.

24 «The techniques and stratagems utilized by Lope to negotiate a path of prudence between the acceptable and the unacceptable in political commentary in the commercial theater» (2000, p. 12). Para McKendrick: «The Spanish theatre no less than the English was a potential arena for subversion - moral, religious, political. This is why it was licensed and censored, this is why it was attacked and opposed» (p. 107). Por esto, se necesitaban técnicas especiales para obtener un decir sin decir. Para percibir los límites que establece ante la posibilidad de críticas veladas, ver su discusión de La estrella de Sevilla (2000, pp. 164-165). 
cos en ensayos publicados en el 200025. Tres años más tarde, aparece la segunda edición del libro de Brown y Elliott sobre el palacio del Buen Retiro, esta vez traducido al español. Aquí reafirman más contundentemente su visión de la fiesta palaciega como crítica al palacio. Vuelven al esbozo de Lotti transformado por Calderón y proclaman: «Pero Calderón transformó al gigante de Lotti en esclavo de Circe, dando ocasión con ello a una serie de equivalencias. La del palacio de Circe y el Buen Retiro estaba clara. También la de Ulises y un Felipe IV de quien se esperaba que suspendiera sus placeres para capitanear a su pueblo en la guerra. ¿Y acaso Circe no podía ser el conde-duque, que durante demasiado tiempo había tenido esclavizado al rey?» ${ }^{26}$.

En el grupo que trata de frenar esta tendencia se encuentra Ignacio Arellano quien en 2005, como ya hemos señalado, aconseja contra excesos interpretativos. Es así que llegamos a los dos artículos de 2006 y de 2008 escritos por Santiago Fernández Mosquera y sus consejos sobre interpretaciones políticas intercalados en su edición de la segunda parte de las obras de Calderón (2007). Él va más allá que lo dicho por McKendrick y Arellano, realzando la importancia del decoro. No se puede «insultar» a un rey y a un valido en una representación en palacio. Circe no puede representar a Olivares pues tal equivalencia «más allá de perder toda proporción y rotura del decoro habría llevado a la desgracia a quien los hubiese propuesto y planeado» ${ }^{27}$. Su rechazo de una interpretación ya tan generalizada, se basa en parte, entre otros, en tres argumentos (1) La ausencia del alegórico gigante ermitaño que representaría la Virtud en Lotti no facilita la identificación del Retiro con los jardines de Circe. Calderón lo transforma en el jocoso gigante Brutamonte que no tiene nada de alegórico y mucho de entremesil. (2) Calderón no podía haber previsto la guerra con Francia y así incluir crítica al Retiro como lugar al que se escapa el rey en una situación bélica. Y (3) no hay nada en la recepción de la obra, sea por el embajador toscano o por el rey y el valido que indiquen que se hubiera visto tal crítica. Si la hubiera habido, Calderón

${ }^{25}$ En un ensayo sobre Dosso Dossi y Calderón me dedico a estudiar la relación entre la pintura de Circe hecha por el Italiano y su impacto en Cosme Lotti y Calderón, reitero la interpretación política de El mayor encanto, amor.

26 Brown y Elliott, 2003, p. 207.

27 Fernández Mosquera, 2007, p. xxv. 
no se hubiera convertido en uno de los favoritos poetas de palacio. Las advertencias de Fernández Mosquera llevan claramente a cuestionar estas interpretaciones, aun las menos excesivas, pues la historia de la época muestra lo que le ocurrió a algunos poetas irreverentes: Villamediana fue asesinado y Quevedo fue exiliado varias veces. ¿Hemos llegado pues al fin de esta línea interpretativa, o es este el fin de otra etapa crítica cuyo arte al igual que la figura de Circe siempre lleva a nuevas mutaciones, a nuevos descubrimientos? Para poder mirar hacia el futuro pasemos unos momentos recordando el paso.

\section{El retorno de Astrea}

Para poder llegar a comprender la validez y los peligros del método que ha causado tanta discusión, creo que es esencial regresar a los contextos que me llevaron a este tipo de interpretación y estudiar los cambios que han surgido en mi acercamiento, siempre centrado en la presencia de Astrea en Calderón. Mi impulso inicial no fue el de buscar críticas políticas en los textos calderonianos. Simplemente me llamó la atención que ningún calderonista se había dedicado a analizar la presencia de la figura de Astrea en la obra del dramaturgo español, figura que venía ya cargada de una serie de significados desde la antigüedad clásica, desde la noción de la diosa como presagio del retorno de la edad dorada al mundo —edad en que los dioses convivían con los seres humanos en una armonía perfecta - hasta la cristianización del mito en donde Astrea profetizaba el nacimiento de Cristo y una nueva edad basada en el cristianismo. La falta de estudios sobre Astrea en el arte y literatura españolas del Siglo de Oro contrastaba y aun contrasta con lo mucho que se ha escrito sobre esta diosa en otras literaturas de la época. Se ha estudiado, por ejemplo, la presencia de Astrea en el Orlando furioso, donde Andronica profetiza el futuro imperio de Carlos $\mathrm{V}^{28}$. Pasando de Italia a Francia, se ha analizado la uti-

28 Según Eric MacPhail, Ariosto escribe su poema durante un momento muy difícil en la historia de Italia: la invasión francesa de 1494, el saco de Roma en 1527, la caída de la Republica de Florencia en 1530, etc. Estos eventos llevaron a un frenesí profético que también incluía la astrología y apuntaba a la conjunción de 1524 . Es en la tercera edición de 1532 donde se añade al Canto 15 la profecía de Andronica donde se habla del futuro descubrimiento del Nuevo Mundo y la venida del Empe- 
lización de la diosa para alabar al rey Enrique IV de Francia, al igual que su presencia en la novela pastoril L'Astrée ${ }^{29}$. Pero es en Inglaterra donde Astrea ha recibido más atención. El conocido estudio de Frances A. Yates examina los elogios poéticos a la reina Elizabeth I donde se le representa como una nueva Astrea. Con la llegada de la edad de hiero, Astrea había dejado este mundo y regresado a los cielos donde se había transformado, en típico catasterismo clásico, en una de dos constelaciones: Libra o Virgo (justicia y virginidad). Elizabeth representaba para poetas tales como Shakespeare y Spenser el ideal de la castidad/virginidad y justicia que traería con su reino una nueva edad de oro. Esta tradición continuó con Jacobo I de Inglaterra. Con su entrada en Londres en 1603 este rey es aclamado como un nuevo Augusto cuyo reino acabará con el exilio de Astrea en los cielos y establecerá una nueva edad de oro. Ben Jonson escribe para Jacobo The Golden Age Restor'd, donde vemos cómo Astrea desciende desde los cielos para recrear la edad de oro. Al enterarse, los demi-dioses (los cortesanos) danzan para el rey ${ }^{30}$. Después de escribir The Return of Astraea, encontré que la crítica sospechaba que esta alabanza poética es ficción, ya que Jacobo no se acerca a los momentos dorados del reinado de Elizabeth ${ }^{31}$. Aun el mismo Shakespeare, según C. B. Hardman, muestra en Winter's Tale que la perfección es una ficción en

rador Carlos V, quien va a restaurar la edad de oro. Aunque Ariosto sigue a Virgilio, va más allá, pues los escritores clásicos no podrían comprender los nuevos descubrimientos en los que vemos un Carlos V que cruza los pilares de Hércules: «Through imitation, Ariosto perpetuates Virgil's voice, thus vindicating the vatic claims of the Aeneid, while also disclosing the failures of prophecy to grasp the spontaneous course of history» (Mac Phail, 2001, p. 34).

29 «There was a widespread belief that the conversion of Henry IV signalized a new and more liberal era dawning in the religious history of Europe, and it is this universal religious hope which gives a particular poignancy to the French Astraea, whose Return becomes an elaborate and esoteric cult in L'Astrée, the pastoral romance by Honoré d'Urfé in which Henry IV himself appears under a thin disguise» (Yates, 1975, p. 210).

${ }^{30}$ Parry, 1981, p. 52.

31 Sobre la doble función (crítica y celebrativa) de los halagos poéticos a Jacobo I, ver Sharpe, 1987. 
este mundo ${ }^{32}$. O sea que Astrea generalmente connota la alabanza, pero puede incluir crítica $^{33}$.

Ya que Astrea fue utilizada en Inglaterra para alabar a la monarquía en los siglos dieciséis y diecisiete, pensé poder descubrir en la obra calderoniana contextos políticos.Y los textos demuestran que desde el inicio del reinado de Felipe IV se utilizaba su figura para alabar al rey. Los poetas lo retrataban como monarca que atraería a la diosa desde los cielos y así establecería una nueva edad de oro. Ya en la primera fiesta teatral que celebraba al nuevo rey, dos dramaturgos competían en su alabanza. Lope de Vega en su Vellocino de oro alababa al rey a través de la orden de caballerías del vellocino, a la que pertenecían los Habsburgos. Mostraba cómo al rey le pertenecía la aventura del vellocino ya que él había nacido en el signo de Aries, cuyo mito era el de este carnero dorado. En competencia con Lope,Villamediana también incluye en su espectáculo una doble alabanza a Felipe IV. La gloria de Niquea hace alusión a Astrea en la loa. Aquí, la figura de la Edad, celebrando el cumpleaños del rey relaciona su nuevo poderío con el regreso de la edad de oro: «En un águila bañada en ascuas de oro que, batiendo las alas parecía que le servía de alfombra la región del aire, bajó otra ninfa que representaba la Edad, pero tan bella que parecía imagen de aquellos dorados siglos que han aguardado tantos» (p. 1160). Esta ninfa alude a la diosa:

\author{
Siempre feliz, y tan capaz de aumento, \\ soberano Señor, tu imperio sea, \\ pues dejó de pisar el firmamento \\ por asistir a tu gobierno Astrea. (vv. 121-124)
}

32 «It is clear to all that the eulogy which represents a monarch's reign as a return to a golden age is substantially the fiction of a political image-maker» (1994, p. 229).

${ }^{33}$ El protestantismo inglés también escogió a Astrea para cultivar la tradición milenaria y el apocalíptico retorno de Cristo. Por ejemplo, Andrew Marvell le dedica un poema a Cristina de Suecia, «Ingelo», en donde ella representa a Astrea que traerá consigo la paz con el retorno apocalíptico de Cristo. La alabanza esconde un quehacer político - la necesidad de su alianza con Cromwell. El propósito del poema, entonces, es: «to evoke a pre-eminent classical prophet in the context of a topical historical situation, and to re-define the Virgilian prophecy in eschatological terms. The poem reflects an ambition, for to imitate Virgil was to identify with a prophetic tradition» (Stocker, 1987, p. 167). 
Astrea, quien había dejado este mundo con la llegada de la edad de hierro, convirtiéndose en la constelación Virgo/Libra, regresa ahora al mundo como había profetizado Virgilio para anunciar una nueva edad de oro regida por un supremo imperio. Aquí Villamediana nos asegura que Felipe IV será tal figura. Y no es Villamediana el único que utiliza a Astrea para alabar al nuevo rey en 1622. Lo hace también Lope de Vega en la loa a La niñez de San Isidro ${ }^{34}$. El mismo Calderón ya había utilizado esta figura en La vida es sueño, donde Rosaura/Astrea cae del caballo, cae dentro del reino de Polonia y puede decirse que cae de los cielos para señalar la llegada de una nueva edad de oro en la que Polonia representa a España. Una vez establecida el importe laudatorio de Astrea durante el reino de Felipe IV, me dediqué a estudiar dos espectáculos palaciegos El mayor encanto, amor y Los tres mayores prodigios. Después de leer y releer los textos, me pareció que la presencia de Astrea y las alabanzas al reino escondían elementos críticos. En primer lugar, Astrea pasaba a ser la criada de una maga con poderes demoníacos.Y en segundo lugar, el palacio de Circe al que llega Ulises en El mayor encanto, amor podría muy bien recordar el nuevo palacio en cuyos jardines se representaba el espectáculo. El lujo del palacio contrastaba con una crisis económica e intensificaba tensiones políticas. En El mayor encanto, amor, no se le nombra la casa del sol, sitio del rey planeta, sino el alcázar de la luna ${ }^{35}$. Ya que el Palacio del Retiro fue ideado por el Conde-Duque de Olivares, sería posible identificarlo con Circe/luna. Olivares reflejaría entonces los rayos del Sol, el poder del rey planeta. Un dato que no llegué a resaltar en mi estudio anterior es la reacción de Astrea como criada de Circe. Lo que ocurre es que Astrea no se muestra nada contenta de su papel, pues su ama transforma hombres en animales: "Vestales vírgenes Diana celebra... / Entre animales y fieras / somos vírgenes bestiales» (pp. 39-40). Parece como si Olivares/Circe hubiera encarcelado a la diosa de la edad de oro en su palacio. Esto podría significar que para Calderón las alusiones poéticas a Astrea eran mera propa-

34 «En el tiempo feliz que reina Astrea / por Felipe divino, con decoro / debido a su valor, para que vea / tantos siglos perdido el siglo de oro» (Lope de Vega, 1967, p. 308).

35 Calderón, Primera parte de comedias, 2007, p. 90. 
ganda y no apuntaban a una renovación política ${ }^{36}$. Al final de la obra Astrea se lamenta de su falta de libertad, pero al hundirse el palacio de Circe, la maga libera a «Cuantos espíritus tuve presos, sujetos y humildes» (p. 105). Pero aún sin desarrollar esta ultima clave, no pude escribir de la obra como mera alabanza al poder. Ahora bien, en muchos otros textos estudiados en The Return of Astraea, desde La gran Cenobia hasta El monstruo de los jardines no llegué a percibir un contexto político definido y me dediqué a analizar las obras desde otros puntos de vista ${ }^{37}$. Lo interesante de todo esto es que mi intención fue la de investigar contextos astrológicos, míticos y laudatorios — nunca fue la de escudriñar la obra en busca de críticas. Fue por eso por lo que me sorprendió encontrar un contexto crítico en El mayor encanto, amor y Los tres mayores prodigios.

Mucho después me di cuenta de que tales contextos también podían vislumbrarse en La vida es sueño - obra escrita años antes de la fiesta palaciega que nos concierne ${ }^{38}$. Sólo quiero recordar que aquí tenemos un experimento astrológico basado en eventos celestiales que ocurrieron alrededor del nacimiento del futuro Felipe IV y que no mostraban claramente si sería buen o mal rey ¿Cómo puede interpretarse la aparición de una nueva estrella en los cielos? ¿Y qué decir de la conjunción Saturno/Júpiter en Sagitario? Aldrete de Soto en su Discurso de la cometa de 1682 todavía recuerda tales eventos: «Y no es nuevo en la astrología que cometas y estrellas nuevas signifiquen nacimientos de monarcas grandes; pues en el año 1604 apareció una estrella cometa en el signo de Sagitario, que predomina en España y por ella juzgó el doctísimo Campanela y otros astrólogos de aquel tiempo, el nacimiento de la majestad del señor rey don Felipe Cuarto el Grande» ${ }^{39}$. Lo que no menciona Aldrete es que Felipe también nació en tiempos de un eclipse de sol. El ser llamado rey planeta se pres-

36 "The debasement of Astraea in the play is further indicated by the fact. That she is paired with Clarín, the lowliest of the two graciosos, whom Circe eventually transforms into a mona... As a sign of chastity she is paired with a servant whose transformation represents his own bestial nature» (De Armas, 1986, p. 146).

37 Otras obras donde no llegué a encontrar un contexto político incluyen: El gol fo de las sirenas, Ni amor se libra de amor, La Puente de Mantible y Los tres afectos de amor. Para una lista de obras que utilizan a Astrea, ver De Armas 1986, p. 68.

38 Ver De Armas, 2000 y 2009.

39 Hurtado Torres, 1984, p. 110. 
ta a la ironía. Y el hecho de que Segismundo nació bajo tal horrendo eclipse, puede muy bien ser clave política astrológica. El lector o espectador de La vida es sueño puede preguntarse quién es realmente Segismundo: un rey planeta o un rey eclipsado. Esta pregunta puede servir de punto de partida para el estudio del retorno de Astrea como clave mitológica y astrológica que nos lleva a cuestionar el momento político $^{40}$.Y justamente, al final de El mayor encanto, amor, Circe, al destruir su palacio describe cómo el humo «al sol eclipse» (p. 105). Los puntos de contacto entre La vida es sueño y El mayor encanto, amor, subrayan la relación textual entre las dos obras: Calderón incluyó su obra maestra como la primera pieza en la primera parte de sus obras, mientras que El mayor encanto amor aparece como la primera obra en la segunda parte de sus comedias. Ambas obras no sólo incluyen el personaje de Astrea sino también el de Clarín. Éste, como instrumento musical alerta a los espectadores de que hay un misterio escondido en las obras. Recordemos que Clarín amenaza a Clotaldo: «y que si el tal Clarín suena / podrá decir cuanto pasa» ${ }^{41}$. Clarín invita a que el espectador o lector estudie los secretos escondidos en las claves astrológicas y mitológicas de estas obras.

Por otra parte, no cabe duda de que la presencia de Astrea en todas estas obras es un signo abiertamente laudatorio. Brown y Elliott nos recuerdan que Olivares atrae a toda una serie de poetas que circularán alrededor del rey Sol y de su privado. Y que entre estos poetas estaba Calderón quien, como explica Fernández Mosquera: «sus buenas relaciones con el rey y el valido que le granjearon no sé si su amistad, pero no pocas prebendas, como la cruz de Caballero de Santiago» ${ }^{42}$. El poeta, según parece, siempre debe de complacer al mecenas. Recordemos el gran ejemplo de la pintura renacentista. Es bien sabido que Carlos V había escogido a Ticiano como su pintor oficial pues dibuja al rey de manera que su quijada algo grotesca se convierte en una expresión de determinación ante el enemigo ${ }^{43}$. ¿Cómo, entonces,

40 Si observamos el descenso de Astrea vemos cómo esta diosa celeste ayuda a transformar a Segismundo en un príncipe menos salvaje, más prudente, pero, al mismo tiempo, casa con Astolfo y parte a Moscovia. ¿A quién pertenece, entonces, la diosa que conlleva el Siglo de Oro?

41 Calderón, Primera parte de comedias, 2006, p. 49.

42 Fernández Mosquera, 2008, p. 211.

43 Panofsky, 1969, p. 85; De Armas, 2006, pp. 118-120. 
reconciliar el decoro y la prudencia utilizado por Ticiano para alabar a su mecenas con mis investigaciones sobre Calderón ${ }^{44}$ ?

\section{Las transformaciones de Circe}

Debido al papel de Astrea y a su círculo astrológico y mitológico, a las pinturas prudentes como las de Ticiano, hay que añadir la pintura atrevida. ¿Qué pensar, por ejemplo, de Velázquez como pintor de la corte? ¿Qué decir de su Marte melancólico ${ }^{45}$ ? ¿O de su retrato del futuro Carlos II con un enano ${ }^{46}$ ? ¿O cómo descifrar la pintura de Rodolfo II como Vertumnus, obra de Giuseppe Arcimboldo? En esta última, una cornucopia de legumbres y flores se metamorfosea en la figura de la primavera, dios grotesco que esboza la imagen del emperador. Según Giancarlo Maiorino: "As a figure of multiple —if not mesmerizing - indirections, Vertumnus unveils the "royal sun" hiding a "monster" within. One disguises the other»" ${ }^{47}$. El rey es como monstruo y el monstruo se convierte en rey.Y, como explica Evans, la pintura representa la máscara y la metamorfosis típica del mundo cortesano. Además, cada legumbre, cada flor, puede tener un significado especial que crea un sistema de correspondencias y oposiciones alentando al espectador a descubrir las cualidades (o errores) del empera-

44 Calderón imita este tipo de aproximación al rey en Darlo todo y no dar nada (1635) cuando Alejandro Magno «rechaza el retrato que le ha pintado Timantes por haber suprimido el defecto que el Emperador tenían en un ojo, e igualmente el de Zeuxis por haber resaltado el defecto, aceptando complacido sólo el de Apeles, quien, habiéndolo pintado de perfil, ni ha suprimido ni ha mostrado el ojo defectuoso» (Ruiz Ramón, 2008, p. 461).

45 Jonathan Brown rechaza una de las interpretaciones modernas más difundidas: «that the picture makes veiled allusions to Spain's declining military fortunes and the weakening will to continue to fight her many enemies» (1986, p. 168). ¿Podría esta pintura y su interpretación recordar las interpretaciones políticas de El mayor encanto, amor donde encontramos a Ulises en postura y actitud similares a las del dios de Velázquez?

46 Para Frieder, este tipo de pintura de Velázquez: «mocked the pretensions of courtiers and favorites, and were perhaps a plea for a Peak king to take his rightful place as head of state. The antics of court jesters drew attention to their defects, but also pointed an accusing finger» (2004, p. 17).

47 Maiorino, 1991, p. 77. 
dor ${ }^{48}$. A pesar de su figura grotesca, el emperador Rodolfo II apreciaba el arte de Arcimboldo quien estaba encargado de organizar las fiestas cortesanas en Praga ${ }^{49}$.

Tal pregunta nos lleva al meollo del asunto. ¿Cuáles son los límites del atrevimiento? Creo que la respuesta ya se vislumbra en la segunda fase crítica, donde se subrayan las constantes transformaciones del sentido de la obra a través de Circe. Pasa de ser una maga controladora que representa con claridad los poderes de Olivares para dominar al rey/Ulises a convertirse una figura multidimensional con la que la figura del privado asume una personalidad más atrayente. En otro momento, la crítica dibuja a la maga como figura transformadora y civilizadora: ella es el espíritu del Buen Retiro que lleva a la contemplación de cómo se debe reinar. Circe, entonces representa los poderes metamórficos del poeta y de su obra. Calderón no es ni prudente ni atrevido sino que elabora en El mayor encanto, amor, una obra casi tan compleja en significado como La vida es sueño. Mientras que en ésta tenemos un experimento astrológico que cuestiona el resultado de las influencias planetarias y zodiacales en Segismundo/Felipe IV, la fiesta palaciega es experimento metamórfico con claves multivalentes. Los poderes de Circe, o del poeta, tienen una magia tan extremada que sus claves verbales y visuales pueden encaminarnos a interpretaciones opuestas: Circe como un Olivares controlador; Circe como el espíritu del Buen Retiro ${ }^{50}$.Ya Virgilio la había mostrado como

48 Evans, 1977, pp. 173-174.

49 Evans, 1977, p. 166.

${ }^{50}$ La presencia de tales opuestos puede muy bien tener su origen en las diferentes representaciones de la maga en Homero, Virgilio y Ovidio. Como bien explica Judith Yarnall, Circe en Homero es una figura ambigua. Puede ser benéfica y lo es para con Odiseo. Pero para Ovidio es la personificación de la lascivia: «The Circe of the Metamorphoses is aggressive and vengeful but every bit as powerless to control her own heart». Yarnall, 1994, p. 89. En los libros XIII y XIV de su famosa obra, el poeta romano narra el viaje de Eneas y cómo tiene que pasar entre Escila y Caribdis. Ovidio siempre amontona historias y así pasamos eventualmente a Circe. Escila era una joven ninfa, amiga de Galatea, perseguida por un cíclope gigante. Y Escila misma, al negarle el amor a Glauco, lo impulsa a que se vengue de ella con los poderes de Circe. Es así que la maga la transforma en esa criatura monstruosa. La furia de Escila es tal que roba los compañeros de Ulises y hunde galeones troyanos. Circe, entonces es una fuerza que se conjura contra los héroes, Ulises y Eneas, sea en su propio palacio o a través de su monstruosa criatura. 
cruel, y había relacionado a Eneas y a Ulises con Circe. Los poetas del círculo de Felipe IV lo alaban como nuevo Ulises, como descendiente de Eneas ${ }^{51}$. Un público cortesano comprendería muy bien que Felipe debe escapar de las transformaciones de la maga. Al lograrlo, la obra se convierte en panegírico del rey. Y Aurora Egido ha mostrado como: «Numerosos textos del Siglo de Oro acogen a la maga como símbolo de la mujer que atrae al hombre hacia el vicio y lo humilla convirtiéndolo en animal $\aleph^{52}$. O sea que, Circe puede verse como fuerza educativa para el Ulises que triunfa. El mayor encanto, amor es una nueva Circe que atrapa a los cortesanos en un laberinto de transformaciones ${ }^{53}$. Cada interpretación es una transformación de un texto ya imbuido de metamorfosis.

Es este juego el que libra a Calderón de tener que descifrar sus propias claves. Este tipo de enredo ingenioso es el que libró en muchos casos a Ovidio de la mirada nociva de Nerón. Pero al fin, no se escapa. Ovidio es exiliado. Como bien avisa Cervantes: «hay poetas que a trueco de decir una malicia, se pondrán a peligro que los destierren a las islas de Ponto» (p. 157). Y, escritores españoles de la época también son encarcelados. Pero Calderón se arma no sólo de una compleja mitología cuyas claves sutiles transforman una y otra vez los significados, sino también de toda una serie de defensas retóricas de gran ingenio. Contemplemos dos o tres de ellas a través de las pinturas de Arcimboldo, pintor que era bien conocido en la España de los Austrias como ha demostrado Margarita Levisi y Steven N. Orso. Ocho de estas pinturas estaban en el dormitorio real (Cuarto de las Furias) del Alcázar de Madrid ${ }^{54}$. El espectáculo palaciego no es sólo

51 Marie Tanner ha mostrado que la Casa de Austria se relacionaba con Eneas y los troyanos (1993, p. 137).

52 Egido, 1994, p. 12.

53 Estudiando una serie de grabados del texto ovidiano, Jean Jeanneret explica que muestran «creation in progress, chaos to be fashioned» (2001, p. 112).

54 En el apartamento de las Furias, un dormitorio real, un visitante observó en 1626: «eight paintings of the Four Elements and of the Four Seasons that were versions of the eight grilli - fantastic bust-length figures composed of animals, plants, or inanimate objects that pertained to the elements or seasons that the figures represented- that Arcimboldo had invented and presented to the Holy Roman Emperor Maximilian II in 1569. Most likely either Maximilian or his successor, Rudolf II, had sent the eight to Philip II as a gift» (Orso, 1986, pp. 162-163). Kaufman explica que se trata de otras versiones de estas ocho pinturas junto con el Mayordomo y el Camarero 
palabras, es también un vistoso banquete de los sentidos preparado por la magia de Calderón y Lotti. Arcimboldo sabe crear figuras humanas de frutas, legumbres, aves, libros. Sus pinturas son un engaño a los ojos, pues cuando creemos ver a una diosa o a un emperador, lo que estamos viendo es una figura compuesta, una colección zoológica o botánica. Calderón expande e invierte la noción del engaño a los ojos:

ULISES Esto ya no es engaño del oído.

Clarín Ni de los ojos, jay de mí!, lo ha sido.

Ulises No, puesto que sus hojas

Verdes pendían y descienden rojas. (pp. 14-15)

Las extrañas figuras de Arcimboldo aparecen en esta instancia como una mujer herida en forma de árbol con hojas sangrientas. De igual manera, el espectáculo calderoniano exhibe sus maravillas cuyo propósito es exaltar la majestad, enaltecer el palacio del Buen Retiro con la pompa del poder. Pero, tras la figura espectacular, se esconden unas colecciones de palabras y mitos, de imágenes y efectos de tan diversas significaciones que nos llevan de aquí a allá en busca de soluciones. Sería casi imposible demostrar la existencia de la malicia tras las claves. Pues al apuntar las claves críticas, podríamos ver igualmente lo opuesto. O sea que Circe puede verse in bono o in malo. Ya Arcimboldo se recreaba con la reversibilidad. Si miramos uno de sus cuadros parece ser una fuente llena de legumbres. Pero si le damos la vuelta, vemos un hombre con un casco. Es así que la amplitud de interpretaciones esconde y delata los secretos de la obra. Esta reversibilidad también se relaciona con el arte anamórfico de la época, donde se ven diferentes imágenes si se observa la pintura desde varios puntos de vis$\mathrm{ta}^{55}$. Sebastián Neumeister cita el fin de la Fábula de Andromeda y Perseo:

de Vinos (2009, p. 59). Espero poder completar un estudio que compara las obras de Arcimboldo con Calderón en un futuro cercano.

55 En la época la pintura anamórfica revela distintas formas si se observa de diferentes maneras. Si por un lado, la acumulación de claves abre la posibilidad de diversas interpretaciones, la anamorfosis invita a que el espectador complete un cuadro desde una de las perspectivas. Jean Jeanneret explica: «They definitely made room in their texts and paintings for the reader or spectator and left him the task of completing, arranging, elucidating. They appealed to his intelligence, stimulated his imagination, challenged his reflexes» (2001, p. 257). 
«miren como juegan, iqué va por todos!» (p. 48). Para él esto significa que Calderón y sus escenógrafos realizan «representaciones teatrales abiertas a toda clase de comprensión e interpretación Y como no es el autor de una obra de arte que decide el destino de ésta, sino el espectador o lector, es posible y hasta preciso añadir otros significados al primero, el de la acción dramática» ${ }^{56}$. Pero las claves escondidas del juego a veces brotan peligrosamente a la superficie. Se pueden tomar las mismas palabras de Circe para asociar el palacio del Buen Retiro con su espacio de oscuras magias. Circe explica que al amarse, Flérida y Lísidas "profanaron el retiro de mi palacio». Así es que no hay que internarse en las claves mitológicas para encontrar paralelos entre el retiro de Circe y el de Felipe y Olivares. Ni hay que salir del texto para ver cómo Circe ha atrapado a Astrea. La diosa de la edad de oro no quiere formar parte del panteón de Circe/Olivares.

Para mí Calderón no es un mero adulador que limita los mensajes de su propia obra. Recordemos que una y otra vez Calderón presenta en su obra el conflicto entre padre e hijo, como bien ha notado Alexander Parker e Ignacio Arellano ${ }^{57}$. Este fue un conflicto que existió en la vida del dramaturgo. Pero podemos ir más allá. Esta rebeldía de Calderón es dibujada en la figura de Segismundo, y yo añadiría, en su sutil forma de rechazar la autoridad paternal del privado en El mayor encanto, amor quien controla al rey con fiestas y alabanzas. Toda una serie de escritores subraya la importancia de la crítica velada, desde Saavedra Fajardo que reconoce la murmuración como herramienta para la libertad de la república hasta Barrionuevo que muestra como desde el mismo púlpito «no prediquen al rey tan claro» ${ }^{58}$. Recordemos que Bances Candamo proclama que el decir sin decir es necesario para la instrucción del príncipe. Explica que el oído «es gran privado de los príncipes, pero mortal enemigo de los privados... llenándolos de guardas para esconderlos de la verdad $»^{59}$. Bances cita su comedia El esclavo en grillos de oro en su propio tratado: "Quien al Príncipe ha ocupado / mal, a todos a ofendido». Lo que aconseja Ban-

56 Neumeister, 2000, p. 133.

57 Arellano, 2006, pp. 25-27.

58 Greer, 1991, p. 81; Barrionuevo, 1968, vol. 1, p. 172. El predicador en este caso es el padre Nicolás Bautista.

59 Bances Candamo, Teatro de los teatros, 1970, p. 56. 
ces, es lo que creo que está haciendo Calderón —hablarle sigilosamente a Felipe IV, para abrirle los ojos y oídos, mientras que Olivares se los cerraba al monarca con "fortísimas cerraduras y candados»" de adulación. Pero ¿Cómo seguir las propuestas de Bances si el privado está presente? Pues, distrayéndolo con la complejidad de hechizos verbales y espectaculares. Hay, pues, dos Circes en la obra de Calderón (el poeta y el privado).

Calderón brilla en grillos de oro, halagando al rey y sirviendo a sus ministros ${ }^{61}$. Hace posible una serie de interpretaciones, conjurando claves que se metamorfosean en sus muchos significados. Puede que si nos encontrásemos con un espectador algo malicioso, para usar el término de Cervantes, éste no podría sino observar el paralelo entre el jardín de Circe y los jardines del Palacio del Buen Retiro. Tal espectador recordaría que sólo meses antes, Lope de Vega había escrito su famoso poema rechazando el retorno de la edad de oro y dándole la espalda a Felipe IV ${ }^{62}$. El Buen Retiro podría recordar los dorados siglos, pero también podría transformarse en la infame Domus Aurea construida por Nerón para sus placeres y violencias, como lugar en el que Ovidio pudo revelar un secreto, que, aunque escondido en sus transformaciones, fue descubierto ${ }^{63}$. Otros maliciosos o des-

${ }^{60}$ Bances Candamo, Teatro de los teatros, 1970, p. 56. Sobre la obra de Bances Candamo ver el estudio de María Cristina Quintero, quien explica: «The contrast between Trajan's greatness and the pathetic reality embodied by Charles must have produced a particularly violent instance of dramatic irony that could not have been lost on the Court audience» (1998, pp. 316-317).

${ }^{61}$ Bances Candamo, Teatro..., 1970, p. 57. La metáfora de Bances Candamo no es del todo original. Tratando de consolar a Campanella por su prisión, el Cardenal Trejo explica: «Julio César, apresado por los piratas, sufrió mucho en Imali. Devuelto a la libertad — sujeto en cadenas de oro- subió a la suprema magistratura de la república; y cuando cayó mortalmente herido por el puñal de Bruto en el Senado, fue cuando se dio cuenta de que había vivido con más seguridad prisionero de los piratas que descuidado de ocultos enemigos... El reino es una especie de cárcel. Grillos de oro se le llama a la administración de la república» (López de Toro, 1962, pp. 173-174).

${ }^{62}$ En El Siglo de Oro Astrea, bajo el reinado de Felipe IV, ha dejado el mundo y Lope se lamenta de la falta de favor de los reyes. Según Juan Manuel Rozas López, Lope terminó su vida «en acusaciones directas a Felipe IV, como las de Huerto deshecho y El Siglo de Oro, y tal vez con una burla sangrienta en la Gatomaquia» (1982, p. $55)$.

${ }^{63}$ El palacio de Nerón se había perdido entre las ruinas de Roma, pero excavaciones durante el Renacimiento lo recobraron hundido bajo la tierra. Una serie de cuevas llevaban a los turistas a ver este suntuoso lugar. Ver De Armas, 2004. 
contentos también verían el palacio como un sitio donde se escondía una fallida política exterior. Serviría para reemplazar el famoso Palazzo del Té, posiblemente el palacio más famoso de Europa en el momento. Localizado en Mantua, recordaba el ducado italiano perdido por la política de Olivares cuatro años antes del espectáculo calderoniano ${ }^{64}$. Los jardines de Circe también contrastarían con la crisis agraria de la época ${ }^{65}$.Y ¿Qué decir de los muchos ataques contra el privado como hechicero? Allí estaba, como una nueva Circe, usando los filtros de Leonerilla para controlar al rey. No hay que olvidar que una vez que Olivares pierde el favor, la más atractiva invectiva contra él es la de ser mago. Y, como Circe, Olivares es también un gran astrólogo. Así nos lo recuerda Ana Caro en $1637^{66}$.

Y ¿quiénes serían los maliciosos que leerían la obra en clave crítica? Como nos recuerda Studnicki-Gizbert, estamos en un momento de grandes confrontaciones políticas. Sabemos que la reina Isabel de Borbón, incluyendo todo su séquito, quería limitar y hasta quebrar la influencia de Olivares sobre el rey. Ella y sus damas podrían observar con malicia a Circe como la figura maléfica del privado que debería ser reemplazado por la buena reina. Hay otro ejemplo aun más revelador. Como respuesta a la generosidad del genovés Carlo Strada quien había invitado a Felipe, a la reina y a Olivares a cenar en su casa y también les había ofrecido piedras preciosas, joyas y muebles de gran lujo, el converso de ascendencia portuguesa, Manuel de Cortizos prepara "the most dazzling party of the 1637 winter season» ${ }^{67}$. Poco más de un año después de la fiesta de Calderón, crea un jardín primaveral en el invierno de Madrid. Un mundo pastoril que incluye naranjales y perales en la ermita de San Bruno, una de las trece en el Retiro, acoge a los soberanos y cortesanos y es allí donde se ofrece un gran banquete. No habría por qué sorprenderse. Cortizos y sus compatriotas

${ }^{64}$ Elliott, 1986, pp. 337-358.

65 Elliott, 1986, p. 410.

66 Ana Caro alude a Olivares como nuevo Atlante (1951, p. 15) y como gran astrólogo (1951, p. 16).

${ }^{67}$ Ver Studnicki-Gizbert, 2007, p. 151. Manuel Cortizos de Villasante nació en Valladolid en 1603. Fue asentista y factor de Felipe IV. Su riqueza e influencia fue tal que contribuyó grandes sumas para la construcción del Retiro y la decoración de San Bruno, una de las trece ermitas en los jardines del Buen Retiro. Murió en 1650. Ver Brown y Elliott, 1980, pp. 100-101; y Kamen, 1997, p. 295. 
ya habían gastado grandes sumas en el palacio y jardines del Retiro. El ambiente del banquete no es uno de armonía pastoril: «One imagines the laughter and the courtesies being constantly cut by sharp glances between the groupings of revelers in the hermitage's courtyard. The courtiers, the counselors, the bankers: all together and each duly noting the movements and conversations of the others ${ }^{68}$. Los genoveses como Strada se conjuraban contra los portugueses como Cortizos.Y éste se dedicaba a alagar a Olivares pues formaba parte del grupo de conversos portugueses que el privado utilizaba como instrumento para destruir el poder de los banqueros genoveses ${ }^{69}$. Los conversos no querían permanecer fuera del centro de poder como fue el caso del judío errante en el auto de Calderón, El nuevo palacio del Retiro $(1634)^{70}$. Y en contra de todos estos, se hallaba un grupo que sospechaba del poder de todo extranjero y quería retornar a un imperio donde el poder económico debía centrarse en la corona. No cabe duda, entonces, que, como en este banquete de 1637, las fiestas en el Buen Retiro podrían parecer obras festivas y hasta carnavalescas. Pero aunque el rey parece divertirse, a su lado se susurran las malicias que amenazan al privado y a su imperio.

Para resumir. El mayor encanto, amor, incluye la figura de Astrea como signo de que la obra tiene un diseño laudatorio. La diosa de la justicia y de la castidad ha servido por más de dos lustros como insignia del retorno de la edad de oro bajo el reinado de Felipe IV y su valido, el Conde-duque de Olivares. El nuevo Palacio del Buen Retiro parece ser reflejo de esta edad en la que dioses cortesanos regidos por un buen rey disfrutan de una celebración que conjura una visión placentera del presente y del futuro, plena de posibilidades. Para aquellos

${ }^{68}$ Ver Studnicki-Gizbert, 2007, p 152.

${ }^{69}$ Como explica Elliott de Olivares: «If he placed his hand skillfully he could use the Portuguese to break the stranglehold of the Genoese financial system, but he had to move with care» (1986, p. 301).

70 «Calderón depicted the new palace as a symbol of the heavenly kingdom, with the wandering Jew (a not entirely unsympathetic figure) being turned away from its gates. Diego Suárez, the adroit secretary of the council of Portugal, could easily insinuate to the Portuguese community that the best way to avoid such a humiliating exclusion was to establish a permanent symbol of its fidelity to church and king inside the grounds of the Retiro itself. Under his aegis, large funds were mobilized for the construction in 1635 of the ornate hermitage chapel dedicated to the patron saint of Portugal, Saint Anthony of Padua» (Brown y Elliott, 1980, p. 100). 
que formarían un auditorio más crítico, aunque prudente, la obra, aunque laudatoria presentaría de manera decorosa una muy útil moraleja. El rey no puede dejarse entretener por los placeres de esta nueva edad que está siendo labrada en palacios y premáticas. Debe siempre estar conciente de su labor infatigable como cabeza de un gran reino. Esta doble interpretación sosiega el espíritu de los oyentes pues presenta claramente las posibilidades de éxito pero muestra que todavía hay mucho que hacer. El rey, el privado y el cortesano dejarían la representación maravillados ante las magias de un teatro que ya es tan complejo y espectacular como el de cualquier corte europea. La representación con sus muchas metamorfosis ha sido símbolo de poder y de innovación. Este nivel de contento, sosiego y deseo de seguir adelante es más que suficiente. No hay que ir más allá, buscando interpretaciones extrañas y peligrosas. No hay que dejarse llevar por murmuraciones de genoveses o de judíos portugueses o de panfletos antisemíticos ${ }^{71}$. Pero aquellos que se mostraran descontentos, llevados de un ingenio melancólico, podrían ver otros diseños y designios. Después de todo, Calderón ha construido su obra utilizando claves que son por sí mismas complejas metamorfosis, engaños a los ojos, plenas de reversibilidades, de anamorfosis y de excesos que despistan. Astrea es Virgo o Libra, signo celestial. Pero aquí es una criada que no quiere servir a Circe y su magia demoníaca. Mientras que algunos poetas proclamaban la edad de oro, otros, ya desengañados, estaban convencidos de que Astrea había dejado el mundo. Y el pueblo siempre miraba con cierto desasosiego el excesivo poder del privado. Podía muy bien ser un hechicero quien, al igual que Álvaro de Luna, había embrujado al rey. Es así como se podría forjar una interpretación basada en las claves mitológicas, en las que el privado se ha convertido en Circe y así controla al rey/Ulises. Y este diseño se puede entrever en el texto. No es que el texto lo diga. El texto es laudatorio y prudente. Pero deja abierta la posibilidad de esta otra interpretación. No, no creamos en ella. La crítica del privado como hechicero es algo para panfletos anónimos y poemas satíricos como La cueva de Meliso en la que Olivares consulta al mago maligno. No, tal ingeniosa interpretación llevaría a peligrosos pensamientos y dudas. Alegrémonos ante el

71 Serían los portugueses los que preferirían una interpretación laudatoria de Olivares quien tenía una actitud positiva hacia conversos y judíos. 
retorno de Astrea. Impulsemos a Ulises a dejar a un lado a Circe y olvidémonos de los problemas del reino. Es día de fiesta y la representación ha mostrado el poder del rey y de su valido. El fuego que destruye a Circe es también el fuego de la noche de San Juan, que da fuerzas al sol para que, en su momento de debilidad, no se eclipse ${ }^{72}$. El reino se regocija y se refuerza, las guerras extranjeras y la incertidumbre económica no tienen por qué preocupar en tal noche de espectáculo. El poderío español no está en declive. Llegarán nuevos triunfos, como los del maravilloso y complejo mundo de esta metamórfica representación. El mayor encanto de Calderón es el de crear una ficción que esconde el desasosiego de una corte en sus últimos días de gloria.

72 Fernández Mosquera explica: «El manuscrito de El mayor encanto... tiene el interés añadido de contar con intervenciones autógrafas de Calderón... Toda la espectacular escena final era sustituida por otra más breve y sencilla escrita al margen por Calderón, tal vez obedeciendo al encargo... que la destinaba a una representación de corral» (2007, p. xxix). 


\section{Bibliografía}

Aercke, K. P., Gods of Play. Baroque Festive Performances as Rhetorical Discourse, Albany, State University of New York Press, 1994.

Arellano, I., El escenario cósmico. Estudio sobre la Comedia de Calderón, Madrid / Frankfurt, Iberoamericana / Vervuert, 2006.

- Historia del teatro español del siglo XVII, Madrid, Cátedra, 2005.

Bances Candamo, F., Teatro de los teatros de los pasados y presentes siglos, ed. D. Moir, London, Tamesis, 1970.

Barrionuevo, J. de, Avisos. (1654-1658), ed. A. Paz y Meliá, Madrid, Ediciones Atlas, 1968, 2 vols.

Blue, W. R., Comedia: Art and History, New York, Peter Lang, 1989.

Brown, J., Velázquez, New Haven / London, Yale University Press, 1986.

- y Elliott, J. H., A Palace for a King. The Buen Retiro and the Court of Philip $I V$, New Haven, Yale University Press, 1980.

- Un palacio para el rey. El Buen Retiro y la corte de Felipe IV, ed. revisada y ampliada, Madrid, Taurus, 2003.

Calderón de la Barca, P., Andrómeda y Perseo, ed. R. Maestre, Almagro, Museo Nacional del Teatro, 1994.

- Primera parte de comedias, ed. L. Iglesias Feijoo, Madrid, Biblioteca Castro, 2006.

- Segunda parte de comedias, ed. S. Fernández Mosquera, Madrid, Biblioteca Castro, 2007.

Caro, A., Contexto de las reales fiestas que se hicieron en el palacio del Buen Retiro a la coronación de Rey de Romanos y entrada en Madrid de la señora princesa de Cariñán, ed. A. Pérez Gómez,Valencia, Talleres de Tipografia Modernos, 1951.

Cervantes, M. de. El ingenioso hidalgo Don Quijote de la Mancha, ed. A. A. Murillo, Madrid, Castalia, 1978, 2 vols.

De Armas, F. A., The Return of Astraea. An Astral-Imperial Myth in Calderón, Lexington, University of Kentucky Press, 1986.

- «The Enchantments of Circe: Dosso Dossi and Calderón's El mayor encanto, amor", en Calderón, Protagonista eminente del barroco europeo, ed. K. Reichenberger, Kassel, Reichenberger, 2000, pp. 175-192.

- "Segismundo/Philip IV: The Politics of Astrology in La vida es sueño», Bulletin of the Comediantes, 53, 2001, pp. 83-100.

- "Nero's Golden House: Italian Art and the Grotesque in Don Quijote, Part II», Cervantes, 24, 1, 2004, pp. 143-171.

- «Papeles de Zafiro: Signos politico-mitológicos en La vida es sueño», Anuario calderoniano, 2, 2009, pp. 75-96.

Egido, A. «Estudio», en Pedro Calderón de la Barca, Los encantos de la culpa, ed. J. M. Escudero, Kassel, Reichenberger, 2004. 
Elliott, J. H., The Count-Duke of Olivares: The Statesman in an Age of Decline, New Haven / London, Yale University Press, 1986.

Evans, R. J. W., Rudolf II and his World, London, Thames and Hudson, 1977. Fernández Mosquera, S., «El significado de las primeras fiestas cortesanas de Calderón", en Calderón y el pensamiento ideológico y cultural de su época: XIV Coloquio Anglogermano sobre Calderón, Heidelberg, 24-28 de julio de 2005, ed. M. Tietz y G. Arnscheidt, Stuttgart, Franz Steiner Verlag, 2008, pp. 209-232.

- «Introducción», Pedro Calderón de la Barca, Segunda Parte de Comedias, Madrid, Biblioteca Castro, 2007.

Frieder, B., «Telling the Truth in Baroque Spain: Past and Present in the Jester Portraits of Velázquez», Discoveries: South-Central Renaissance Conference News and Notes, 21, 2004, pp. 5-18.

Greer, M. R., The Play of Power. Mythological Court Dramas of Calderón de la Barca, Princeton, Princeton University Press, 1991.

- «El poder en juego: El mayor encanto, amon», en Estudios sobre Calderón, ed. J. Aparicio Maydeu, Madrid, Istmo, 2000, vol. 2, pp. 649-692.

- «Los dos cuerpos del rey en Calderón: El nuevo palacio del Retiro y El mayor encanto, amon, en El teatro clásico español a través de sus monarcas, ed. L. García Lorenzo, Madrid, Fundamentos, 2006, pp. 181-202.

Hamilton, D. B., Virgil and The Tempest. The Politics of Imitation, Columbus, Ohio State University Press, 1990.

Hardman, C. B., "Shakespeare's Winter's Tale and the Stuart Golden Age», Review of English Studies, 45, 178, 1994, pp. 221-229.

Hernández Araico, S., "Génesis oficial y oposición política en El mayor encanto, amon, Romanistisches Jahrbuch, 44, 1993, pp. 307-322.

- «Official Genesis and Political Subversion of El mayor encanto amon, en The Golden Age Comedia. Text, Theory and Performance, ed. Ch. Ganelin y H. Mancing, West Lafayette, Purdue University Press, 1994, pp. 119-136.

Hurtado Torres, A., La astrología en la literatura del Siglo de Oro, Alicante, Instituto de Estudios Alicantinos, 1984.

Kaufman, T. D., Arcimboldo. Visual Jokes, Natural History, and Still-Life Painting, Chicago / London, University of Chicago Press, 2009.

Jeannerlet, J., Perpetual Motion. Transforming Shapes in the Renaissance from da Vinci to Montaigne, trad. N. Poller, Baltimore, The Johns Hopkins University Press, 2001.

Kamen, H., The Spanish Inquisition. A Historical Revision, London, Weidenfeld and Nicolson, 1997.

LeVisi, M., "Las figuras compuestas en Archimboldo y Quevedo», Comparative Literature, 20, 1968, pp. 217-235.

López de Toro, J., «Respuesta del cardenal Trejo a una carta de Tomás Campanella», Revista de estudios políticos, 122, 1962, pp. 161-178. 
Maiorino, G., The Portrait of Eccentricity. Arcimboldo and the Mannerist Grotesque, Pennsylvania, Pennsylvania State University Press, 1991.

MacPhail, E., "Ariosto and the Prophetic Moment», Modern Language Notes, 116, 1, 2001, pp. 30-53.

McKendrick, M., Playing the King. Lope de Vega and the Limits of Conformity, Woodbridge / Rochester, Tamesis, 2000.

Panofsky, E., Problems in Titian. Mostly Iconographic, New York, New York University Press, 1969.

Parker, A. A., "The Father-Son Conflict in the Drama of Calderón», Forum for Modern Language Studies, 2, 1966, pp. 99-113.

Parry, G., The Golden Age Restor'd: The Culture of the Stuart Court 1603-1642, Manchester, Manchester University Press, 1981.

Quintero, M. C., "Monarchy and the Limits of Exemplarity in the Teatro palaciego of Francisco Bances Candamo", Hispanic Review, 66, 3, 1998, pp. 309-329.

Rodríguez Gallego, F., «Sobre el texto de El mayor encanto, amor: a propósito de un manuscrito de 1668", Anuario calderoniano, 1, 2008, pp. 285315.

Rozas López, J. M., Lope de Vega y Felipe IV en el "Ciclo de Senectute», Badajoz / Cáceres, Universidad de Extremadura, 1982.

Ruiz Ramón, F., Celebración y Catarsis (Leer el teatro español), Murcia, Universidad de Murcia / Sucesores de Nogués, 1988.

- «Sobre la doble recepción en La vida es sueño», en Calderón y el pensamiento ideológico y cultural de su época. XIV Coloquio Anglogermano sobre Calderón, Heidelberg, 24-28 de julio de 2005, ed. M. Tietz y G. Arnscheidt, Stuttgart, Franz Steiner Verlag, 2008, pp. 461-470.

Sharpe, K., Criticism and Compliment: The Politics of Literature in the England of Charles I, Cambridge, Cambridge University Press, 1987.

Shergold, N. D., "The First Performance of Calderón's El mayor encanto amon», Bulletin of Spanish Studies, 35, 1958, pp. 24-27.

Stocker, M., "Remodeling Virgil: Marvell's New Astraea», Studies in Phililogy, 84, 2, 1987, pp. 159-179.

Studnicki-Gizbert, D., A Nation Upon the Sea: Portugal's Atlantic Diaspora and the Crisis of the Spanish Empire 1492-1640, Oxford, Oxford University Press, 2007.

TAnner, M., The Last Descendants of Aeneas. The Habsburgs and the Mythic Image of the Emperor, New Haven, Yale University Press, 1993.

Trambaioli, M., «Las empresas dramáticas calderonianas de tema mitológico sobra la educación del perfecto príncipe cristiano", en Actes du Congrès International Théâtre, Musique et Arts dans les Cours Européennes de la Renaissance et du Baroque, ed. K. Sabik, Varsovie, Éditions de l'Université de Varsovie, Faculté des Lettres Modernes, 1997, pp. 269-286. 
- «La faceta lúdica de la mitología en las fiestas cortesanas de Calderón», Texto e imagen en Calderón. Undécimo Coloquio Anglogermano sobre Calderón, St. Andrews, Escocia, 17-20 de Julio de 1996, ed. M. Tietz, Stuttgart, Franz Steiner Verlag, 1998a, pp. 254-271.

- "Tonalidades entremesiles en el teatro palaciego de Calderón», Atti del 1 Seminario Internazionalde sui Secoli d'Oro (Firenze, 8-12 settembre 1997), Firenze, Alinea Editrice, 1998b, pp. 287-303.

VegA, L. De, Obras escogidas, ed F. C. Sáinz de Robles, Madrid, Aguilar, 1967, vol. 3.

Villamediana, Conde de, La gloria de Niquea, en Poesía impresa completa, ed. J. F. Ruiz Casanova, Madrid, Cátedra, 1990, pp. 1149-1227.

WiLks, K., "¿Tan fáciles son mis lazos de romper?": Circe, the Seventeenth Century Theatrical Enchantress, Tesis doctoral, Chicago, 2004.

Yates, F., Astraea. The Imperial Theme in the Sixteenth Century, London, Routledge \& Keagan Paul, 1975.

Yarnall, J., Transformations of Circe. The History of an Enchantress, Urbana, University of Illinois Press, 1994. 